\title{
Training in Actuators, IoT and IP Address for Senior High School Teachers and Students
}

\section{WALUYO, ANDRE WIDURA, DWI ARYANTA, ARSYAD RAMADHAN DARLIS, NANA SUBARNA, RUSTAMAJI, KANIA SAWITRI, DINI FAUZIAH, SYAHRIAL, NIKEN SYAFITRI, FEBRIAN HADIATNA}

\author{
Institut Teknologi Nasional Bandung \\ Email: waluyo@itenas.ac.id
}

Received 30 May 2020 | Revised 05 June 2020 | Accepted 24 June 2020

\begin{abstract}
The third mission of a university is a community service. Based on the mission, this paper presents the activity of community service. The activity was training for senior high school students and teachers. The subjects of the training are actuators, IoT, and IP address. These components or subsystems are very important basic industrial instrumentation for further automation. These subsystems are very correlated with each other. Some actuators are electric, hydraulic, and pneumatic types. There are many applications of IOT and IP addresses, such as smart grids and communications. As a result of these community service activities, additional knowledge of teachers and students regarding the training material is obtained.
\end{abstract}

Keywords: community service, actuator, IoT, IP address, smart grid

\section{INTRODUCTION}

The third mission of a university is reflected in the Tri Dharma activities, following the philosophy mandated by the government, namely education and teaching, research and community service, as well as supporting activities, including institutional development activities. The performance of a university can be measured from the level of success in realizing the mission and goals that have been set. The implementation of Training of Automation System Actuators, IoT and IP Address as Basic Industrial Instrumentation for High School Students and Teachers by the academic staff of the Department of Electrical Engineering, Institut Teknologi Nasional Bandung has been in line with the need for the implementation of quality systems in the management of the three aspects of Tri Dharma activities. The potential and competency of the lecturers should be able to appear to realize to benefit the general public, especially for the community and the students and teachers of the high school / vocational. For that reason, the Department of Electrical Engineering, the Community Service Division in the Department of Electrical Engineering in collaboration with the Bureau of Cooperation and Marketing Planning (BPKP) ITENAS has carried out community service activities in the form of automation system actuators, IoT and IP address training. The high school students are generally relatively low knowledge and skills of industrial 
instrumentation, especially in these subjects. This case causes the competitiveness of human resources (HR) is still low. To provide knowledge for high school / vocational high school students and teachers and operators or factory employees and to become equipped if they want to develop knowledge and skills to be better and more competitive. For providing the knowledge and understanding related to the introduction and deepening of training of Automation System Actuators, IoT, and IP Address as Basic Industrial Instrumentation for High School Students and Teachers by the academic staff of the Department of Electrical Engineering, Institut Teknologi Nasional Bandung. It is necessary to conduct theoretical and practical training related to industrial instrumentation that is appropriate and feasible in the form of counseling and high school.

\section{METHOD}

This activity was carried out in the form of training that consist of theory giving and Laboratory visits conducted in 1 day. The theory about actuators, IoT and IP address was given by the speaker from the Electrical Engineering lecturer at Institut Teknologi Nasional Bandung. Conceptualization of the theory includes to facilitate participants understand theoretical concepts by demonstration and introduction of several practical tools in Telecommunications Laboratories, Automation Laboratories, and Electric Power Engineering Laboratories.

\section{IMPLEMENTATION AND RESULT OF ACTIVITY}

To provide knowledge and understanding to the participants, the Department of Electrical Engineering has conduct a training in the field of industrial instrumentation. The participants are students and teachers of SMK Merdeka Bandung, SMK Angkasa Huesin Bandung, and SMK Ganesha Bandung, as many as 22 people. Some Electrical Engineering lecturers who are willing to donate knowledge and other charities in the field of industrial instrumentation are participate in the activities. The facilities were provided from the Electrical Engineering Department, specifically in the form of handouts, including supporting mathematical theories, telecommunications, including computer networks, basic instrumentation, electrical systems, temperature sensors, induction electric motors and controls, and IoT. While the implementation of counseling and training techniques in the form of material exposure and training in laboratory. Figure 1 shows some pictures of the training activity.

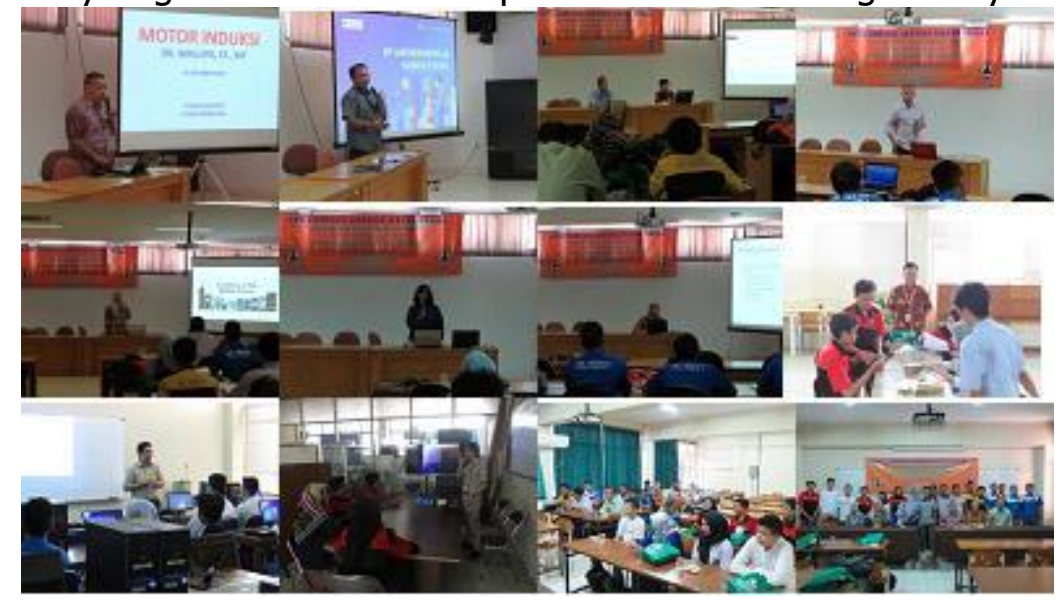

Figure 1. Some pictures of the training activity 
The first subject was induction machines. The induction machines are one of the electric machines which widely applicable as an electric motor in industries. More than $85 \%$ of industrial motors in use are in fact induction motors. It is a constant-speed motor and a few percent speed drop. The stator is similar to that of a synchronous machine and is wound for three phases. Figure 2 shows the stator, wound, and squirrel-cage rotors and the equivalent circuit (Kothari, 2018).

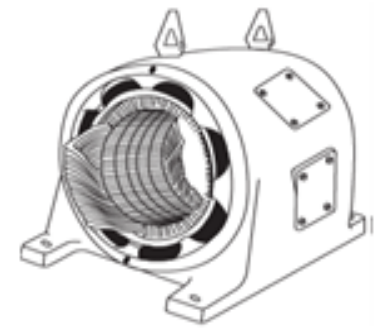

(a) Stator

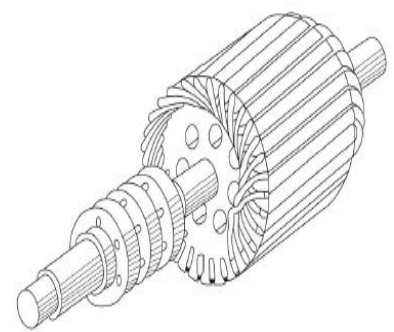

(b) Wound rotor

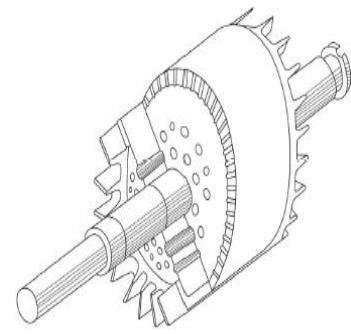

(c) Squirrel-cage rotor

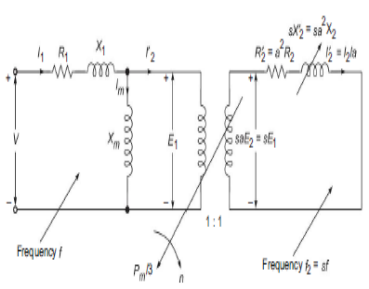

(d) Equivalent circuit

Figure 2. Some parts and equivalent circuit of induction motor (Kothari, 2018)

Induction motor is one of the electric drive machines that are widely used in vehicles, conveyors, pumps, and industrial applications. Induction motors are widely used because of their simple construction, low maintenance, low weight/power, and robust. Several things need to be noted by the behavior of the induction motor including the characteristics: starting, speed, and stops (Hughes, 2006).

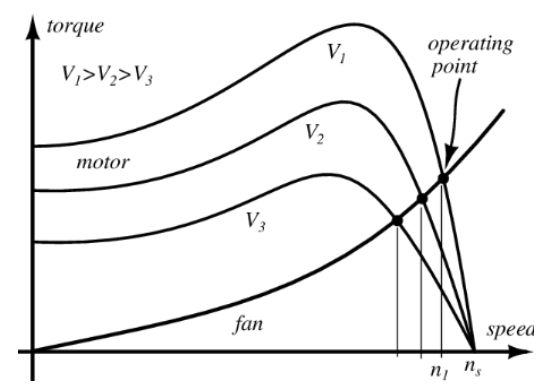

(a)

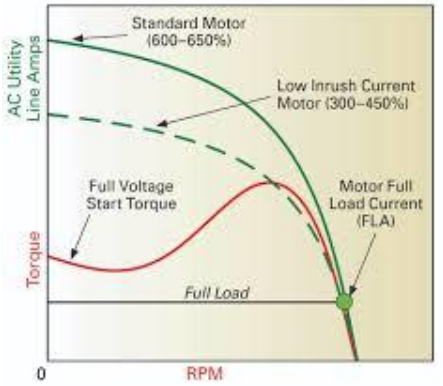

(b)

Figure 3(a). Torque vs speed characteristics, (b). Starting current vs speed (Hughes, 2006)

Figure 3 shows that the induction motor is supplied with a fixed frequency but the voltage varies where $V_{1}>V_{2}>V_{3}$. This characteristic is commonly used to treat the motor when starting so that the starting current can be suppressed. But by reducing the starting current, the starting torque will also go down, so that the minimum torque of the motor must be sufficient to provide acceleration to the load (at least 20\% above the load torque) (Hughes, 2006). Figure 4 shows the control circuit and torque characteristics, current and motor speed using a direct online method (Agrawal, 2001).

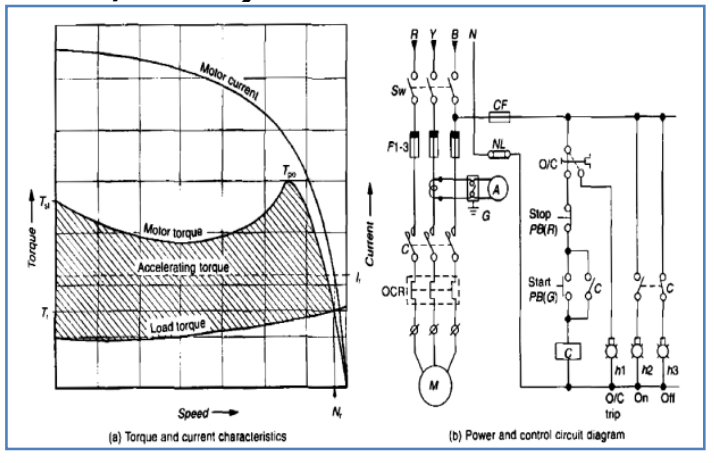


Figure 4. (a). Characteristics of torque and current vs speed (b). Control circuit in the form of contactor (Agrawal, 2001)

Figure 4 shows the control circuit consists of the start, stop, latching, contactor, and indicator lights. It shows that the starting current is very large, usually 6.5 - 12 times $I_{n}$ (Agrawal, 2001). To suppress the stating current can be done by using the starting star-delta method as shown in Figure 3 below (Agrawal, 2001).

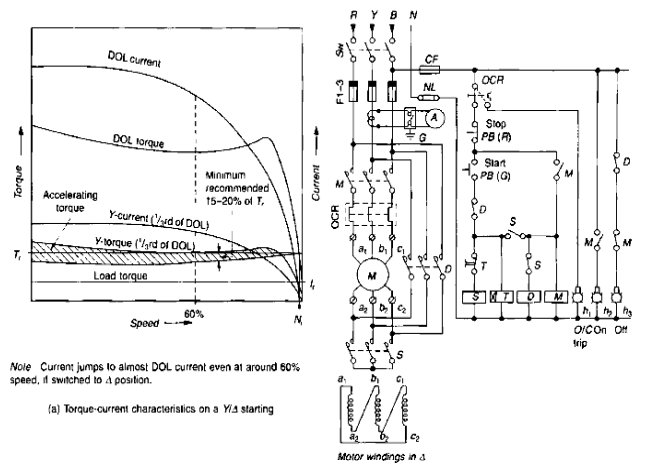

Figure 5. Starting with the star-delta method and its characteristics (Agrawal, 2001)

To suppress the starting current then the control circuit configuration will form a star circuit where the contactor (S) is closed, the contactor $M$ is closed and the contactor $D$ is open. After a few seconds then the circuit will change the configuration to Delta where contactor (s) open, contactor M closed and contactor D is closed (Agrawal, 2001).

At the time of motor in a star configuration, the motor winding is feed by a voltage as Neutral Phase, after to change the delta configuration the motor winding is feed by a phase- phase voltage. In other words, the starting motor voltage is reduced by $1 /$ sqrt(3) of the phase-phase (Agrawal, 2001). To suppressed the starting current can also be done by providing prime resistance so that the current entering the motor can be adjusted in such a way with sufficient to accelerate. The circuit can be seen as shown in Figure 6 below (Agrawal, 2001).

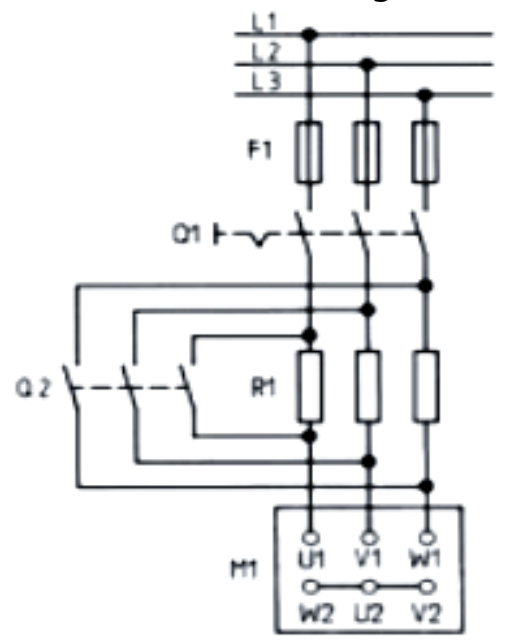

Figure 4. Starting with a resistance method (Agrawal, 2001)

When starting of motor, the contactor Q2 is open and the contactor Q1 is closed so the current will be passed the resistance. After a few seconds, Q2 will close and the current will pass the contactor (Agrawal, 2001). A soft starting method uses a semiconductor circuit to reduce the input voltage on the induction motor as shown in Figure 7 (Irwin, 2001). 


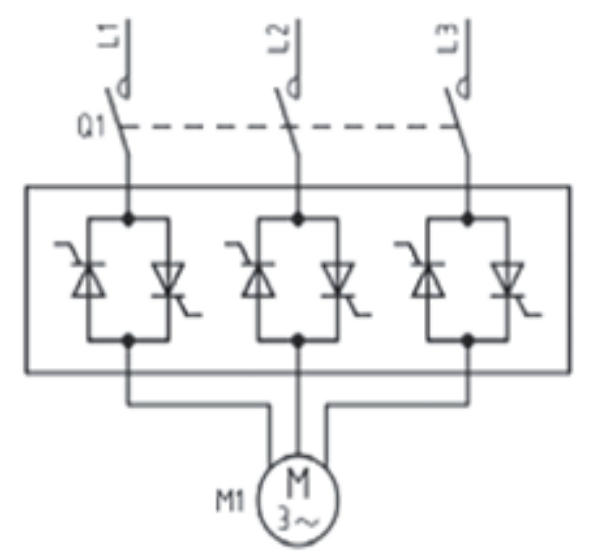

Figure 5. Starting with the soft starting method (Irwin, 2001)

The voltage regulation to the motor is done by using an anti-parallel thyristor circuit so that each voltage entering the phase winding can be controlled. The principle of voltage control is based on the effective value where the effective value obtained from the integration of the voltage function (Irwin, 2001).

Besides that, it is necessary for the safety of people. The safe approach limits for people are shown in Table 1 (Jiguparmar, 2012).

Table 1. Safe approach limits for people (Jiguparmar, 2012)

\begin{tabular}{ccccccc}
\hline Voltage & $214 \mathrm{~V}$ & $11 \mathrm{kV}$ & $33 \mathrm{kV}$ & $66 \mathrm{kV}$ & $132 \mathrm{kV}$ & $\begin{array}{c}275 \mathrm{kV} \text { to } \\
415 \mathrm{kV}\end{array}$ \\
\hline $\begin{array}{c}\text { A person using a } \\
\text { manually operated tool } \\
(\mathrm{m})\end{array}$ & 1.3 & 2.0 & 3.0 & 4.0 & 5.0 & 6.0 \\
\hline $\begin{array}{c}\text { A person using a power- } \\
\text { operated tool (m) }\end{array}$ & 3.0 & 3.0 & 3.0 & 4.0 & 5.0 & 6.0 \\
\hline
\end{tabular}

A further topic is the IP address. It is part of a computer network data communication protocol, as Transfer Control Protocol / Internet Protocol (TCP/IP). Every host and router has an IP address, which encodes the network and host numbers. The combination is unique (Tanenbaum, 2003). IP Address version 4 (IPv4) is the most popular, which is 32-bit numbers (Tanenbaum, 2003).

IP Address version 6 (IPv6) has grown its utilization today and has 128-bit total length divided into 8 16-bit size block, which can be converted into a 4-digit hexadecimal number. IPv6 can be simplified by doing ZEROCOMPRESSION, which is replacing 16 bit zero (0) binary numbers with a double dot (::) and removing the most significant bit (MSB) zero (0) binary number(s) in each block (so that the value remain the same) (Irawan, 2019).

IPv4 class addressing was divided into the five categories as Class $A, B, C, D$ and Class $E$. The class $A, B, C$, and D formats are for up to 128 networks, with 16 million hosts each, 16,384 networks with up to $64 \mathrm{~K}$ hosts, and 2 million networks (e.g., LANs) with up to 256 hosts each. Addresses beginning with 1111 (class E) are reserved for research and future use. Each address is globally unique. For subnetting implementation, the main router needs a subnet mask that indicates the split between network + subnet number and host, as shown in Figure 8 (Tanenbaum, 2003). 


\section{Bits}
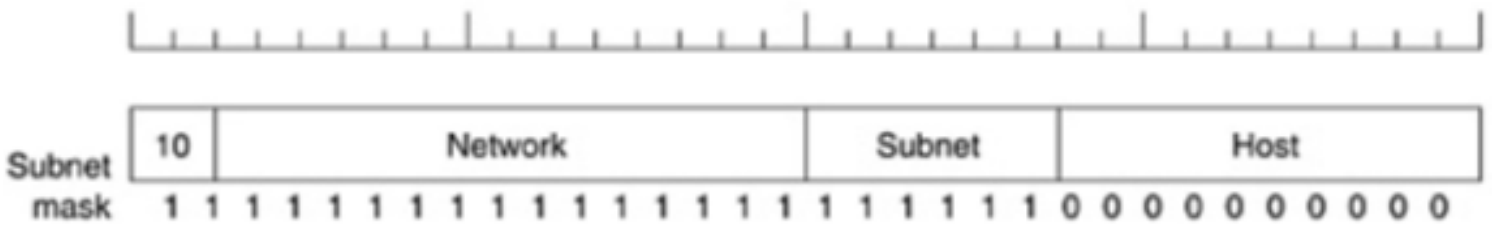

Figure 8. Subnetting mask of the main router (Tanenbaum, 2003)

All the bits allocated to the network address are represented by binary number 1 , in the subnet mask, while all the host address allocation bits will be represented by the binary number 0 (Mikrotik, 2020). In an IP address allocation, there are 3 different IP address functions, including host address, which is an IP address that is given to a network device such as a computer or router so that they can interconnect, and network address, the IP address that represents the address of a network. All hosts on one network have the same network address. the network address is the first IP in an IP subnet. This IP address is divided into several classes. There are several common IP classes, including classes A, B, and C. Classes $\mathrm{D}$ and $\mathrm{E}$ are not commonly used by users. Each address class has a different default subnet mask. The class of IP addresses can be recognized through the first octet. The following is a range of classes $A, B$, and $C$ internet addresses, each with a sample address (Microsoft, 2019).

The further activity was the experiment about networking, i.e. Unshielded Twisted Pair (UTP) cable implementation and Configure Cisco Router. In the first activities, Unshielded Twisted Pair (UTP) cable implementation, the participants made straight cables and cross cables. The order of this activity is to prepare UTP cable, RJ-45 connector, cable stripper, Crimping Tool, and LAN Tester. Set the straight and cross cable pairs are like as Figure 9 (Cisco, 2020).

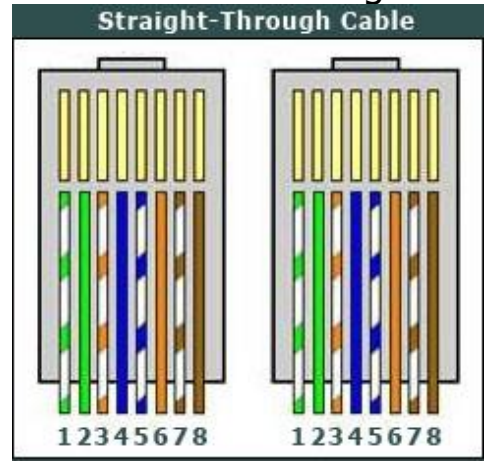

(a) Straight-through cable

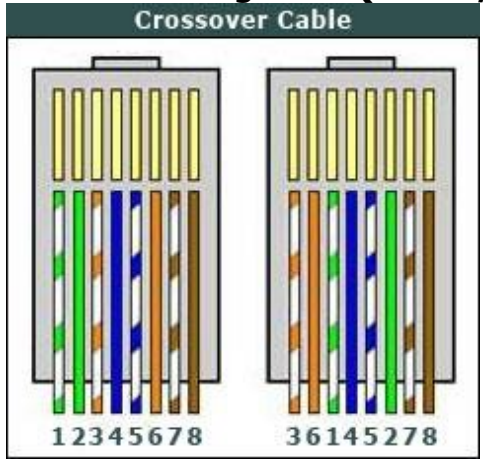

(b) Crossover cable

Figure 9. Straight and cross cable pairs

When ON/OFF occurs on contact, there is an electrical breakdown between contacts. During the breakdown, there are contact damage, high-frequency radiation, and surge voltage as well as current. There are 2 types of breakdown, gas/glow discharge or corona, and metal vapor/arc discharge. A glow discharge is a partial discharge that occurs when the gas between contacts is ionized. $\mathrm{V}_{\mathrm{GD}}$ functions of gas type, spacing, and pressure. For the air gas at standard conditions and 0.0003 inches $(7.62 \mu \mathrm{m})$ gap, $\mathrm{V}_{\mathrm{GD}}$ is 320 Volts $(\mathbf{O t t}, \mathbf{1 9 8 8})$. 


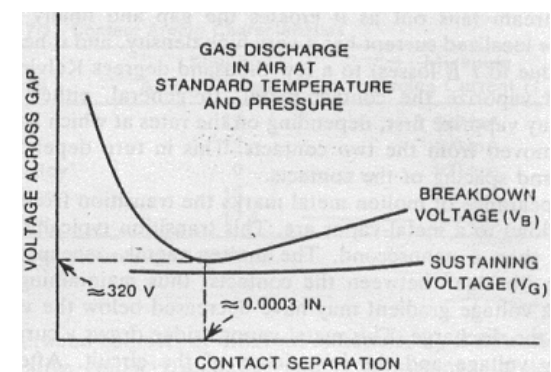

(a) Voltage vs distance

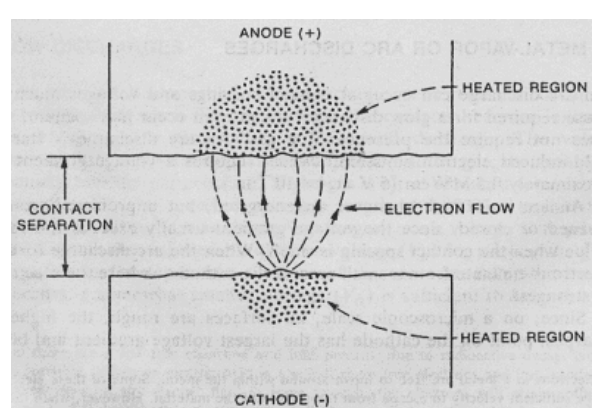

(b) Arc discharge initiation

Figure 10. Voltage versus distance for glow discharge and initiation of arc discharge (Ott, 1988)

An arc discharge can occur at distances and voltages lower than those required by the glow discharge and there is no need for gas. The arc discharge is an induced electron emission field, a breakdown caused by a high electric field due to the sharp tip. $\mathrm{E}_{\mathrm{AD}} \approx 0.5 \mathrm{MV} / \mathrm{cm}$ ( $5 \mathrm{~V}$ with a $4 \times 10^{-6}$ inch space). The arc discharge occurs if the contact (unprotected) is open/close and the distance between the contacts is small. A breakdown, a contact current with a very high density occurs and heats the contact to thousands of ${ }^{\circ} \mathrm{K}\left(\mathrm{P}=\mathrm{I}^{2} \mathrm{R}\right)$. Molten metal is a sign of the transition from electron flow to a metal vapor arc (occurring less than ns) that forms a conductive bridge, as shown in Figure 10 (Ott, 1988).

The actuator is a component or part of a machine that functions for moving and controlling a mechanism or system, for example, to open a valve. The simple term is movers as in Figure 11 (Wikipedia, 2020).

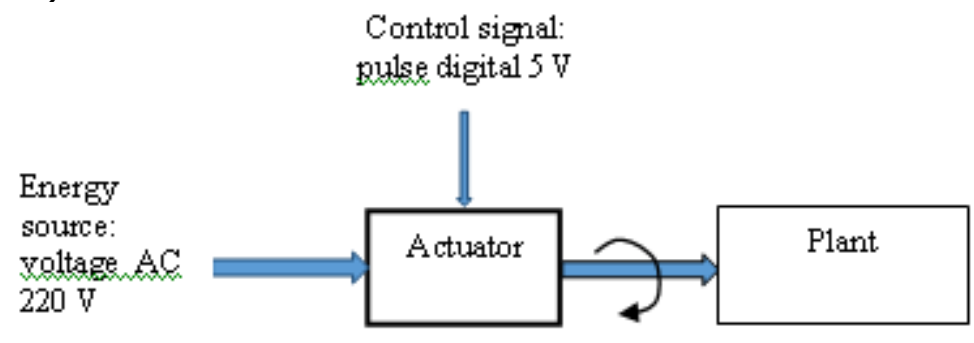

Figure 11. Illustration of actuator work

Actuators require control signals and energy sources. The control signal is relatively low energy and can be either current or electric voltage, hydraulic or pneumatic pressure, or even human power. The main energy sources are electric current, hydraulic fluid pressure, or pneumatic pressure. The actuator responds by converting signal energy into mechanical motion, when receiving a control signal, (Wikipedia, 2020; Johnson, 2013; Sawhney, 1985). Figure 12 shows some types of actuators. 


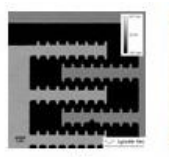

(a)

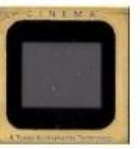

(b)

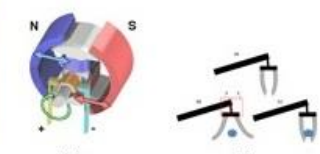

(d)

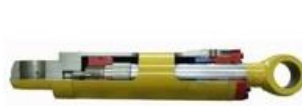

(e)

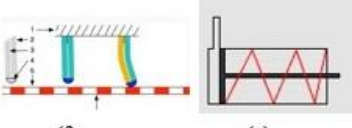

(f)

(g)

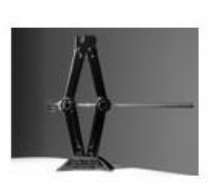

(h)

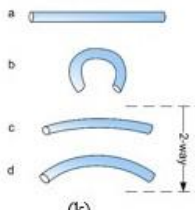

(k)

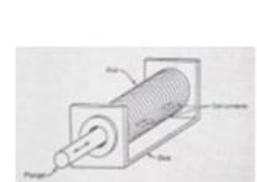

(i)

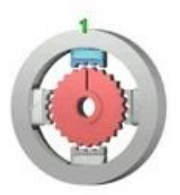

(j)

Figure 12. (a) Comb drive, (b) Digital micromirror, (c) Electric motor, (d) Electroactive polymer, (e) Hydraulic cylinder, (f) Piezoelectric actuator, (g) Pneumatic actuator, (h) Screw jack, (i) Solenoid, (j) Stepper motor, and (k) Shape-memory alloy

Figure 13 shows some controlling ways.

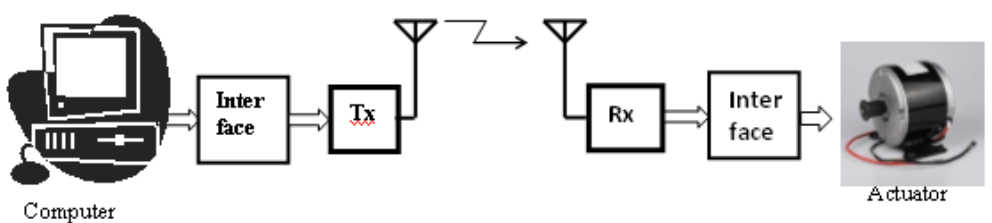

(a)

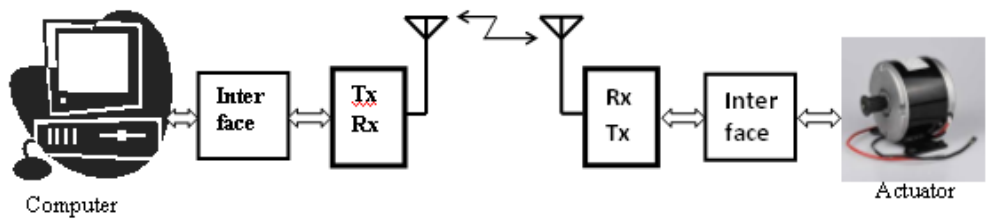

(b)

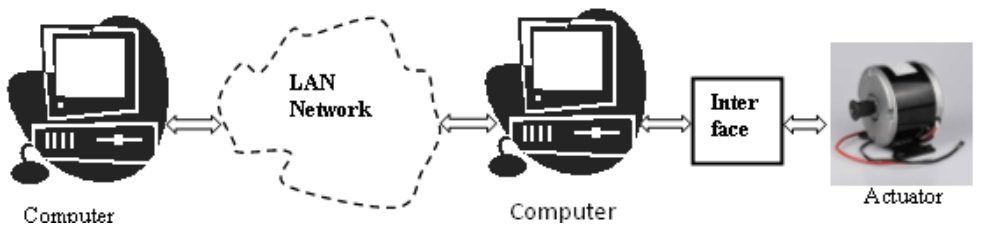

(c)

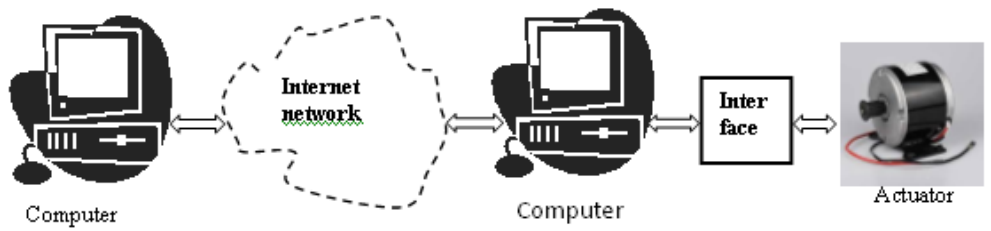

(d) 


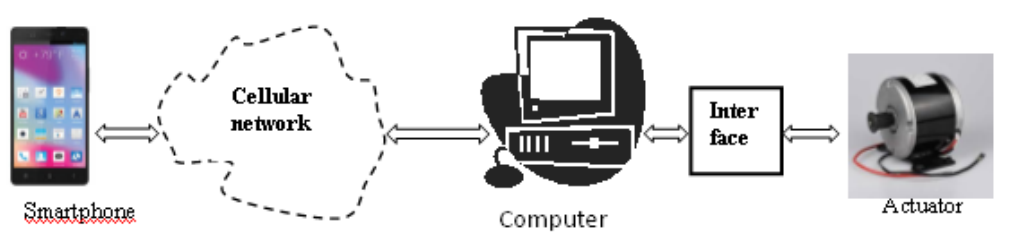

(e)

Figure 13. Various ways of controlling actuator remotely, using: (a) A Radio Transmitter (Tx), (b). A Radio Transceiver, (c). A Local area network (LAN). (d). The Internet Network, and (e). A Cellphone (Smartphone)

The thermal actuators such as copper coil, which is part of a solenoid, can change their resistance due to changes in temperature (Carter, 2016).

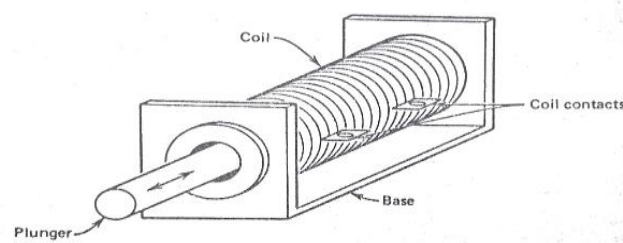

(a)

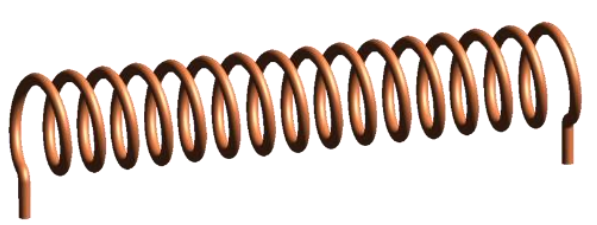

(b)

Figure 14. (a). A solenoid as thermal actuators (Johnson, 2013), and (b). copper coil (Wikipedia, 2020)

The conductor resistance of a copper coil as a function of temperature, by equation (Carter, 2016)

$R(T)=R_{o}(1+\alpha \mathrm{T})$

Where $R_{0}$ is resistance at $0^{\circ} \mathrm{C}$ and $\alpha$ is temperature coefficient of resistance.

A stepper Motor (Carter, 2016; Johnson, 2013) is a motor that can rotate step by step or per step for a full rotation of $360^{\circ}$ if given a pulse input. As an example, a stepper motor has $10^{\circ}$ per step and rotates at $250 \mathrm{rpm}$.

Internet of Things (IoT) is, at any time, a people and thing connection, using any network and any service, with anyone and anything, in any place. Thus, IoT is a huge infrastructure of dynamic global network of internet-enabled entities with web services. One of IoT applications is for a Smart Grid (SG). SG is a communications network, integrated with the power grid to collect and analyze data from transmission lines, distribution substations, and consumers (Ghasempour, 2019).

The IoT is a new generation in information technology. There are two meanings, it's the core and foundation of things that are still the extension and expansion of the internet and its client extends to any object and between objects to exchange information and communicate (Biao Li,2017).

The Revolution Industry 4.0 is influenced by several factors, including the Internet of things (IoT), security network, artificial intelligence, cloud computing, big data, etc (Zenius, 2020). IoT is a concept where internet connectivity can exchange information with each other with the objects around it (Triawan, 2016). The participants learn to use NodeMCU. Some basic experiments performed with this device, including light, LED, and drive the servo motor actuator. Both devices are connected to the NodeMCU which has been supplied with power. The process of monitoring and controlling the LED display and the position of the servo motor through an IoT application is the Blynk app. Figure 15(a), shows the interface of this application. Based on Figure 3(a), this application looks easy to use and has a good display. The concept of this application appears in Figure 15(b). 


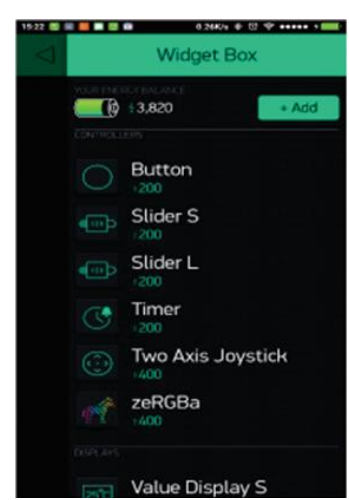

(a) Blynk App

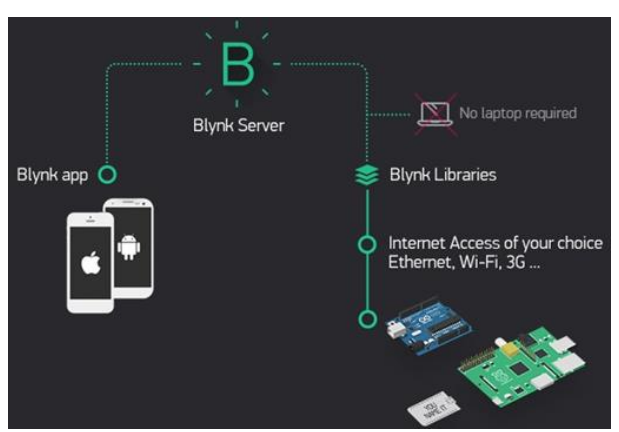

(b) Blynk app concept

Figure 15. Blynk Application (Blynk, 2020)

IoT implies addressing elements such as convergence, collections (repositories), communication, computing, and interconnection between things and/or between things and people/humans (Figure 16).

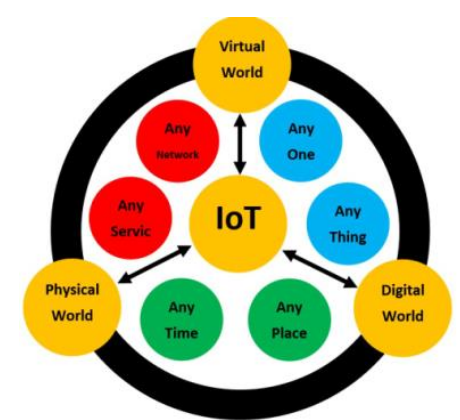

Figure 16. IoT, connections, and related entities (Siozios, 2019)

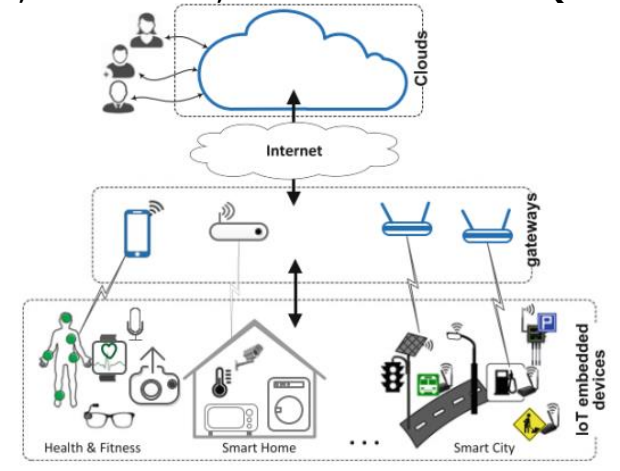

Figure 17. IoT cloud-centric architecture (Siozios, 2019)

Figure 17 depicts the high-level architecture and IoT embedded devices interact with sensors and actuators. The control decision will be made in the cloud, and the result - in the form of control command - will be sent back to the actuator or IoT device. The gateway's role is limited to the seamless integration of IoT devices with the networks (e.g., LAN, network, cellular, etc.) to interface the IoT local area networks with the internet. The gateway bridges transmit it to the cloud server. The cloud servers provide data storage, analysis, and decision-making services (Siozios, 2019).

A smart grid is an electricity network that uses cyber-secure communication technologies, and automated and computer control systems. The smart grid ensures the coordination of all generating facilities, grid operators, end-users, and electricity market stakeholders, so that the system operates efficiently, minimizing costs and environmental impacts and maximizing system reliability, resilience, stability, and safety (SaIman, 2017). Figure 18 shows the difference between before and after the smart grid. 


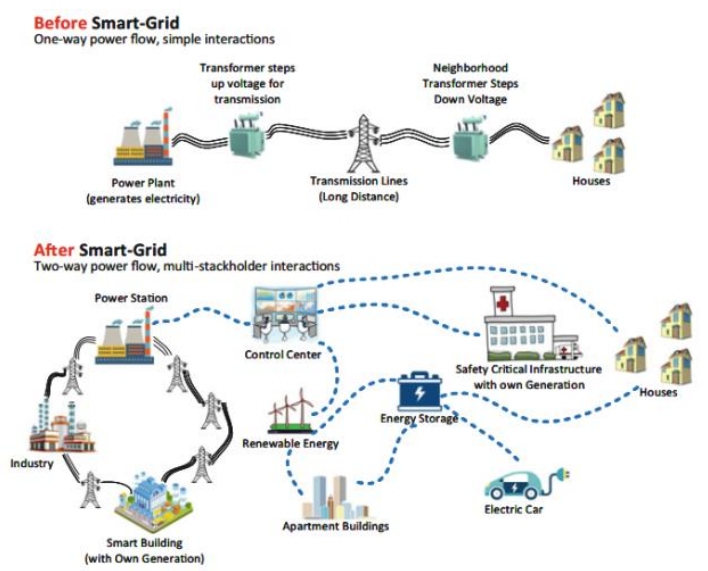

Figure 18. The smart-grid environment within the broader electricity system (Salman, 2017)

A smart grid is one of IoT application domains where generation, transportation, delivery, and electric consumption is improved in reliability, safety, and efficiency. A combining IoT and SG can promote the development of meters and sensors, smart terminals, communication devices and information equipment greatly. IoT can be used to accomplish reliable data transmission in wireless and wired communications (Ghasempour, 2019).

IoT is uniquely identifiable, available anytime and anywhere, has the sensing/actuation capability, is embedded intelligence, has the interoperable communication capability, selfconfigurability, and programmability feature (Minerva, 2015). AI is a device that is equipped by an artificial human cognitive function or ideal rationality, both reasoning-based and behavior-based, that can respond the motion so that the device is not aware of itself or the decision making is beyond the common system, it always enhances its ability based on its previous movement (Russell, 2010). Table 2 shows the rest of the difference between IoT and AI.

Table 3. IoT versus AI (Data-flair, 2019)

\begin{tabular}{ll}
\hline \multicolumn{1}{c}{ IoT } \\
$\begin{array}{ll}\text { IoT generates high-quality statistics and the data } \\
\text { flow is enabled by cloud computing }\end{array}$ & $\begin{array}{l}\text { AI uses cloud computing so that a machine can } \\
\text { learn, think, act and react as well as human }\end{array}$ \\
$\begin{array}{l}\text { The data flow is stored at an area and the identity is } \\
\text { processed, IoT will give the statistic data when it is } \\
\text { needed }\end{array}$ & $\begin{array}{l}\text { The system learns from the error of the running } \\
\text { activity and it always tries to self-evolve for the } \\
\text { better performance }\end{array}$ \\
\hline The system cost is less than USD 50k & \begin{tabular}{l} 
The system cost is between USD 100k and 300k \\
\hline $\begin{array}{l}\text { The system is on a large scale because of the cloud- } \\
\text { based architecture }\end{array}$
\end{tabular} \\
\hline
\end{tabular}

Figure 18 shows the IoT Machine Learning application that can save the industrial cost. 


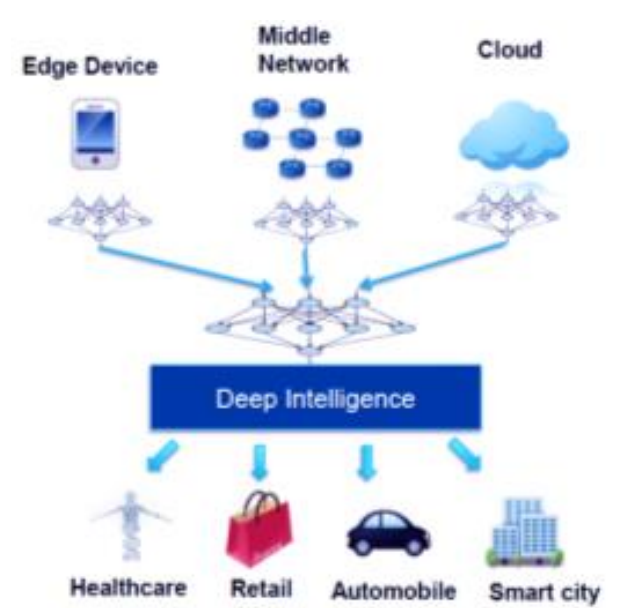

Figure 19. IoT Machine Learning application (Data-flair, 2019)

The application of IoT Machine Learning covers ambient assisted living, adverse drug reaction, internet of m-health things, information of children health, healthcare of community, access of wearable device and semantic medicines, emergency healthcare, embedded gateway configuration, and so on (Dhanvijay, 2019). In smart cities, the application includes smart homes, smart parking lots, weather and water systems, vehicular traffic, environmental pollution, surveillance systems (Arasteh, 2016). For the automotive sector, IoT Machine Learning is used in fleet management, connected cars, automotive maintenance system, autonomous vehicles, in-vehicle infotainment, and telematics (Biz4intellia, 2020). IoT Machine Learning includes smart stores, how to connect customers, smart warehouses, supply chain management, predictive equipment maintenance, (Builtin, 2020).

IoT Machine Learning can shape individual experience. From the obtained data and the conducted learning, the system can give the optimal output which is satisfying the needs of human users. An example of how the process of IoT Machine Learning is shown in Figure 20.

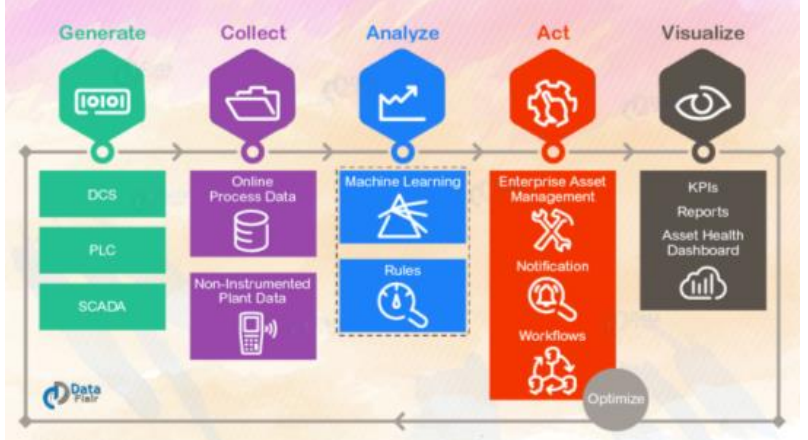

Figure 20. The process of IoT Machine Learning (Data-flair, 2019)

One of Machine Learning's basic knowledge is Artificial Neural-Network (ANN or NN), which is combined with statistics. NN was proposed inspired by the work of the human nervous system. As we know, the human brain structure is remarkably complex. It consists of $10^{12}$ neurons and $6 \times 10^{18}$ synapsis and forms a neural-network (Russell, 2010). The network can be a simple or more complex one, as can be seen in Figure 21. 


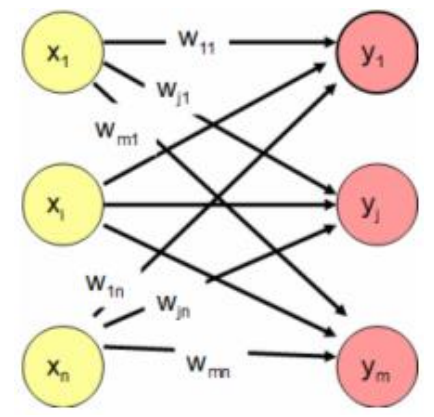

(a)

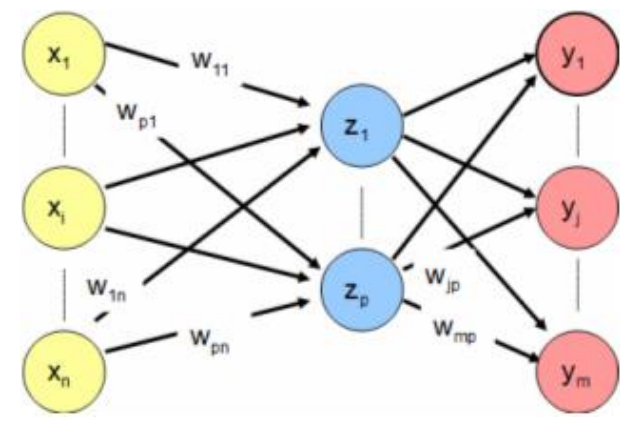

(b)

Figure 21. NN architectures, (a) single-layer network and (b) multi-layer network

The network architecture is determined by the number of inputs and outputs. The number of layers inside is considered by the learning and training requirements.

Overall it can be said that the actuator, IoT and IP address training activities for high school students and teachers are running smoothly and quite effective. This is proven by enthusiasm of participants who took part in the training program from beginning to end in the form material and laboratory visit. Participants are quite cooperative with arrive on time and follow the instructions given by the speaker during the activity take place. therefore, we plan to conduct community service activities for other high schools so that the knowledge provided can benefit many people.

\section{CONCLUSIONS}

Actuator, IoT and IP address training can be done with smoothly and all participants are very cooperative. The results of this activity, participants gained additional knowledge about the material presented, and its application in the form of demonstrations and introduction of equipment through the visit of several laboratories in the electrical engineering department of the Institut Teknologi Nasional Bandung. This training activity is very limited because it is only held for 1 day with very dense material and practice. but we hope that this training can provide benefits for the participants.

\section{ACKNOWLEDGMENT}

The author would like to express my deepest gratitude to SMK Merdeka Bandung, SMK Angkasa Husein Bandung, and SMK Ganesha Bandung for supporting activity as participants and Planning Cooperation Promotion Bureau, Itenas, for supporting a part of the funding.

\section{LIST OF REFERENCES}

Agrawal, K.C. (2001), Industrial Power Engineering and Applications Handbook, ButterworthHeinemann.

Arasteh, H., Hosseinnezhad, V., Loia, V., Tommasetti, A., Troisi, O., Shafie-khah, M., \& Siano, P. (2016). IoT-based Smart Cities: A Survey. 2016 IEEE $16^{\text {th }}$ International Conference on Environment and Electrical Engineering (EEEIC), Florence, Italy. 
Biao Li, Sen Lv, Qing Pan (2018). The Internet of things and Smart Grid, IOP Conf. Series: Earth and Environmental Science.

Biz4intellia, (2020, 28 May). https:// www.bż4intellia.com/blog/iot-applications-in-automotiveindustry/.

Blynk (2020). https://docs.blynk.cc/

Builtin (2020, 28 May). https://builtin.com/internet-things/iot-in-retail-tech-applications.

Carter, P. (2016). Technical Mathematics, Schaum's Outline Series, McGraw-Hill Book Company.

Cisco Team (2020). CCNA RS Module.

Data-flair, (2019 Oct.). https://data-flair.training/blogs/iot-and-machine-learning/accessed in. Dhanvijay, M. M., \& Patil, S. C. (2019). Internet of Things: A survey of enabling technologies in healthcare and its applications. Computer Networks 153, pp 113-131, Elsevier.

Ghasempour, A. (2019). Internet of Things in Smart Grid: Architecture, Applications, Services, Key Technologies, and Challenges. Inventions 2019, 4, 22.

Hughes, A., Drury, B. (2019). Electric Motors and Drives Fundamentals, Types and

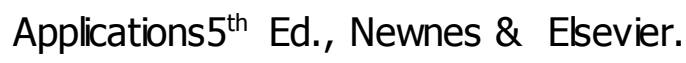

Irawan, B., IP Address Versi 6, (2019, 4 Oct.) online:

https://budhiirawan.staff.telkomuniversity.ac.id/ files/2017/04/15.-Sistem-PengalamatanIPv6.pdf, .

Irwin, J.D. (2001). Power Electronics Handbook, Academic Press.

Jiguparmar (2012, Nov.). Electrical Safety Standards for LV/MV/HV (Part-3), , https://electrical-engineering-portal.com/electrical-safety-standards-for-lvmvhv-part$3 \# 11$.

Johnson, C.D. (2013). Process Control Instrumentation Technology, $3^{\text {rd }}$ ed., John Wiley \& Sons Inc.

Kothari, D.P., Nagrath, I.J. (2018). Electric Machines, 5/e, McGraw Hill Education (India) Private Limited.

Microsoft (2020). https:// support.microsoft.com/id-id/help/164015/understanding-tcp-ipaddressing-and-subnetting-basics

Mikrotik (2020). http:// www. mikrotik. co. id/artikel_lihat.php?id=64.

Minerva, R., Biru, A., Rotondi, D. (2015). Towards a definition of the Internet of Things (IoT). IEEE.

Ott, H. W. (1988). Noise Reduction Techniques in Electronic Systems, $2^{\text {nd }}$ Ed., John Wiley \& Sons. 
Russell, N. \& Norvig, P. (2010). Artificial Intelligence: A Modern Approach. $3^{\text {rd }}$ ed. Pearson. Salman (2017). Introduction to the Smart Grid Concepts, Technologies, and Evolution. The Institution of Engineering and Technology, London, United Kingdom

Sawhney, A.K. (1985). A Course in Electrical and Electronic Measurements and Instrumentation, $4^{\text {th }}$ Ed., Dhanpat Rai \& Sons.

Siozios, K., Anagnostos, D., Soudris, D., Kosmatopoulos, E. (2019). IoT for Smart GridsDesign Challenges and Paradigms, Springer Nature AG, Switzerland.

Tanenbaum, A. S. (2003). Computer Networks, $4^{\text {th }}$ Ed., Prentice Hall, pp. 495-504.

Triawan, M.A., Hindersah, H., Yolanda, D. Hadiatna, F. (2016). Internet of Things using Publish and Subscribe Method Cloud-based Application to NFT-based Hydroponic System, IEEE 6th International Conference on System Engineering and Technology (ICSET). Wikipedia (2020). https://en.wikipedia.org/wiki/Actuator.

Zenius (2020). https://www.zenius.net/blog/21104/revolusi-industri-4-0, 